\title{
TRANSFORMASI LINIER UNTUK PERSOALAN PROGRAM KUADRATIK NOL-SATU
}

\author{
M Khahfi Zuhanda \\ Universitas Medan Area, Medan \\ Surel : Khahfi@staff.uma.ac.id \\ Diterima : 25 Oktober 2017; Disetujui : 01 November 2017
}

\begin{abstract}
ABSTRAK
Program non linier merupakan persoalan yang cukup menarik untuk di bahas oleh matematikawan. Salah satunya program kuadratik nol-satu yang fungsi tujuan dan kendala berbentuk persamaan kuadratik. Program kuadratik nol-satu merupakan kelas khusus dalam pemrograman non-linier karena persyaratan peubah keputusan bernilai nol-satu. Tulisan ini akan mengajukan sebuah teknik untuk menyelesaikan persoalan program kuadratik nol-satu yang dikembangkan oleh Sherali dan Smith. Teknik ini mengubah Quadratic Problems (QP) menjadi kebentuk Bilinier Problems(BP) terlebih dahulu. Akhir dari proses ini mengakibatkan transformasi program kuadratik nol-satu menjadi persoalan linier nol-satu.
\end{abstract}

Kata Kunci : integer, linierisasi, nol-satu, program kuadratik

\section{ABSTRACT}

Non-linear programming is an interesting issue to be discussed by mathematician. One of them is a zero-one quadratic programming, where the objective function and constraints are quadratic equations. The zero-one quadratic programming is a special case in non-linear programming because of the requirement of value variable is zero-one. This paper propose a technique for solving the zero-one quadratic programming problem was developed by Sherali and Smith. This technique converts the Quadratic Problems $(Q P)$ into Bilinier Problems $(B P)$ first. The end of this process will transfrom zero-one quadratic programming to zero-one linear programming problem

Keywords: Integer, Linearization, Quadratic Programming, Zero-One,

objektif kuadratik dengan beberapa kendala

\section{Pendahuluan}

Seiring perkembangan zaman, perkembangan ilmu pengetahuan kini meningkat tajam. Ilmu pengetahuan telah banyak membantu manusia dalam memberikan solusi kompleksnya permasalahan dalam kehidupan sehari-hari. Mulai dari bidang kedokteran, ekonomi, sosial, politik, sumber daya, dan lain-lain. Permasalahan optimasi non linier tak luput dalam memberi kontribusi dalam segala aspek. Dalam beberapa tahun terakhir, telah banyak matematikawan mengembangkan permasalahan non linier, salah satunya program kuadratik nol-satu.

$$
\text { Program kuadratik nol-satu }
$$

merupakan kelas khusus dari pemrograman non linier. Program kuadratik nol-satu ditujukan untuk meminimalkan subjek fungsi kuadratik, dengan kondisi bahwa masingmasing variabel dibatasi nilai nol atau satu. Permasalahan program kuadratik nol-satu sering muncul pada beberapa persoalan seperti telekomunikasi, manufaktur, penjadwalan, dan lain-lain.

Beberapa literatur strategi linierisasi juga telah dilakukan untuk menyelesaikan permasalahan program kuadratik nol-satu menjadi bentuk pemrograman linier integer, mulai dari Gharibi dan Xia [1], dan berkembang menjadi formulasi yang lebih ringkas dan membutuhkan variabel biner seperti yang dilakukan Furini dan Traversi [2], Gharibi [3] mengembangkan Teknik Linierisasi Balas dan Mazzolla program kuadratik nolsatu. De Santis dan Rinaldi [4] mengembangkan reformulasi persoalan kuadratik nol-satu kontinu. Koncherberger, 
Alidaee, dan Rego [5] mengembangkan algoritma Taboo Search untuk menyelesaikan program kuadratik biner.

Permasalahan pemrograman kuadratik nol-satu merupakan salah satu permasalahan optimisasi tak linear yang sangat penting, karena muncul dalam berbagai aspek, termasuk dalam aspek perekonomian, sains terapan, analisis portofolio, dan pengendalian optimal. Salah satu metode yang dapat digunakan untuk menyelesaikan permasalahan pemrograman kuadratik nol-satu adalah dengan teknik linierisasi bilinier yaitu dengan mentransformasikan persamaan kuadratik menjadi bentuk linier. Pada penelitian ini akan dianalisis bagaimana teknik linierisasi program kuadratik nol-satu yang telah diperkenalkan oleh Sherali dan Smith [6] untuk menyelesaikan persoalan program kuadratik nol-satu.

Teknik linierisasi program kuadratik nol-satu lebih efektif dalam menyelesaikan program kuadratik yang memiliki batasan masalah variabel nol-satu. Teknik ini merupakan teknik linieirisasi terbaru untuk persoalan kuadratik nol-satu yang sebelumnya telah diperkenalkan oleh Sherali dan Smith [6]. Lalu dikembangkan kembali oleh Gharibi dan Xia [1] dengan tightness strategy.

Penelitian ini akan menunjukkan secara literatur penerapan linierisasi program kuadratik nol-satu dan menyelesaikan beberapa contoh persoalan numerik program kuadratik nol-satu.

Permasalahan pemrograman kuadratik merupakan salah satu permasalahan optimisasi tak linear yang sangat penting, karena muncul dalam berbagai aspek, termasuk dalam aspek perekonomian, sains terapan, analisis portofolio, dan pengendalian optimal.Banyak ilmuan meneliti program kuadratik,tetapi untuk kasus persoalan program kuadratik nolsatu, teknik linierisasi Sherali dan Smith lebih efektif untuk menyelesaikan proram kuadratik nol-satu. Karena solusi yang dibatasi oleh nolsatu membuat fungsi kuadratik menjadi permasalahan yang baru. Karena variable berorde dua akan sama besar pengaruhnya dengan variabel

berorde satu. Andai di berikan persoalan program kuadratik yang fungsi tujuan dan kendalanya berbentuk persamaan kuadratik dengan variabelnya dibatasi oleh nol dan satu. Dimana persamaan yang berbentuk kuadratik akandi transformasi menjadi linier. Transformasi program kuadratik berakibat penambahan variable dan persamaan kedalam fungsi kendala.
Tujuan dalam penelitian ini adalah menjabarkan dan menganalisa teknik linierisasi untuk menyelesaikanpersoalankuadratik nolsatu..

\section{Pembahasan}

\subsection{Teknik Liniersasi Sherali dan Smith}

Permasalahan program kuadratik merupakan salah satu permasalahan optimisasi tak linear yang sangat penting, karena muncul dalam berbagai aspek, termasuk dalam aspek perekonomian, sains terapan, komputasi, dan komunikasi. Banyak ilmuan meneliti program kuadratik, akan tetapi, untuk kasus persoalan program kuadratik nol-satu, teknik linierisasi Sherali dan Smith lebih efektif untuk menyelesaikan proram kuadratik nol-satu. Karena solusi yang dibatasi oleh nol-satu membuat fungsi kuadratik menjadi permasalahan yang baru.

Berikut ini merupakan bentuk program kuadratik nol-satu

Minimumkan $\quad C^{T} x+X^{T} Q x$

Kendala: $\quad h^{T} x+x^{T} G x \geq g$

$x \in X \subseteq\{x: x$ adalah bilangan biner $\} \subseteq B^{n}(2.3)$

Dimana $Q$ dan $G$ adalah matriks dimensi $n x n$. Dalam linierisasi program kuadratik nol-satu dapat melalui beberapa langkah yaitu:

Langkah 1. Mengubah persamaan kuadratik menjadi kebentuk persamaan bilinier.

Misalkan program kuadratik di transformasi menjadi perkalian antara fungsi linier. Sehingga dapat dinyatakan dalam proses sebagai berikut

$$
\gamma_{\min / \max }^{i}=\min / \max \left\{Q_{i} x: x \in \bar{X}\right\}, \forall_{i} .
$$

Dan $Q_{i}$ merupakan $Q$ baris ke $i$, dan $\bar{X}$ adalah sebuah relaksasi dari $X$ seperti yang ditunjukkan pada persamaan (2.4). Andaikan didefinisikan $\gamma_{\min / \max }^{i}$ sebagai vektor yang mempunyai anggota-anggota $\gamma_{\min / \max }^{i}=$ $1, \ldots, n$ dan misalkan $\Gamma_{\min / \max }=\operatorname{diag}\left\{\gamma_{\min / \max }^{i}\right\}$. Dan didefinisikan pula bahwa

$$
\lambda_{\min / \max }^{i}=\min / \max \left\{G_{i} x: x \in \bar{X}\right\}, \forall_{i} .
$$

Misalkan 


\section{Transformasi Linier Untuk Persoalan Program Kuadratik Nol-Satu}

$\lambda_{\min / \max }^{i}=\left(\lambda_{\min / \max }^{i}\right)^{T}$ dan

$\Gamma_{\min / \max }=$

$\operatorname{diag}\left\{\gamma_{\min / \text { max }}^{i}\right\}$

Maka di reformulasikan persoalan program kuadratik adalah $Q P$ yang juga merupakan bentuk fungsi Bilinear Problem (BP). Maka persoalan $Q P$ dapat dinyatakan kedalam persoalan $B P$, maka diperoleh persamaan yang dapat dituliskan sebagai berikut

$$
\begin{array}{lc}
\text { BP: Minimumkan } & C^{T} x+x^{T} \gamma \\
& Q x=\gamma \\
\text { Kendala } & \\
& \\
h^{T} x+x^{T} \gamma \geq g \\
G x=\lambda \\
& x \in X
\end{array}
$$

Dan diketahui juga bahwa

$$
\gamma_{\frac{\min }{\max }} \leq \gamma_{\min }, \lambda_{\min } \leq \lambda \leq \lambda_{\max }
$$

Langkah 2. Mentransformasi persamaan bilinier dengan mensubtitusi dengan variabel yang baru.

Selanjutnya, proses dilinierisasi kondisi $x^{T} \gamma$ dan $x^{T} \lambda$ dengan perkalian persamaan (2.10) dengan $x_{i}$ dan $\left(1-x_{i}\right)$ dimana persamaan (2.10) $i$ adalah baris ke $i$ dari salah satu bagian vektor pertidaksamaan di persamaan (2.10), $\forall_{i}=1, \ldots, n$. Sehingga diperoleh untuk

$$
x_{i} \gamma_{i}=S_{i} \text { dan } x_{i} \lambda=Z_{i}^{\prime}, \forall_{i}=1, \ldots, n
$$

Misalkan $e$ mempresentasikan sebuah vektor. Maka, BP dapat di transformasikan mengikuti persamaan

$$
\begin{array}{ll}
\text { BP: Minimumkan } & C^{T} x+e^{T} S^{\prime} \\
\text { Kendala } & Q x=\gamma \\
& h^{T} x+e^{T} Z^{\prime} \geq g \\
& G x=\lambda
\end{array}
$$

$$
\begin{aligned}
& \gamma_{\min }^{\prime} x_{i} \leq s_{i} \leq \gamma_{\min } x_{i} \text { dan } \\
& \gamma_{\text {min }}^{\prime}\left(1-x_{i}\right) \leq\left(s_{i} \leq\left(\gamma_{i}-s_{i}\right)\right. \\
& \leq \gamma_{\text {max }}^{\prime}\left(1-x_{i}\right), \forall_{i} \\
& \lambda_{\min }^{\prime} x_{i} \leq z_{i} \leq \lambda_{\min } x_{i} \text { dan } \\
& \lambda_{\text {min }}^{\prime}\left(1-x_{i}\right) \leq\left(s_{i} \leq\left(\lambda_{i}-z_{i}\right) \leq \lambda_{\text {max }}^{\prime}(1-\right. \\
& x i), \forall i
\end{aligned}
$$

Langkah 3. Menambah persamaan pada fungsi kendala akibat penambahan variabel baru pada transformasi sebelumnya.

Perhatikan bahwa persamaan (2.11) menjamin bahwa persamaan (2.12) berlaku untuk $x$ bilangan biner. Dengan memperhatikan struktur pertidaksamaan pada persamaan (2.12) yang dapat dinyatakan sebagai berikut

$$
\begin{gathered}
s_{i}=s_{i}^{\prime}-\gamma_{\min }^{i} x_{i}, \forall_{i} \\
y_{i}=\gamma_{i}-s_{i}^{\prime}-\gamma_{\min }^{i}\left(1-x_{i}\right), \forall_{i} \\
z_{i}=z_{i}^{\prime}-\lambda_{\min }^{i} x_{i}, \forall_{i}
\end{gathered}
$$

Sehingga transformasi persamaan yang baru berdasarkan persamaan (4.13) dapat dinyatakan sebagai berikut

$$
\begin{aligned}
& \text { BP: Minimumkan } C^{T} x+e^{T} s+\gamma_{\min }^{T} x \\
& \text { Kendala } \quad Q x=y+s+\Gamma_{\min } \mathrm{e}
\end{aligned}
$$

Langkah 4. Merelaksasi bentuk BP dari langkah sebelumnya dengan menghapus batas atas dan bawah dari pertidaksamaan persamaan yang baru.

Kemudian, persoalan BP ditunjukkan oleh persamaan (2.14) disederhanakan dengan menghapus batas atas pertidaksamaan untuk $s_{i}$ di persamaan (2.18) dan untuk $\left(\lambda_{i}-z_{i}\right)$ di persamaan (2.19). $\lambda_{i}$ adalah batas bawah pertidaksamaan $\lambda \geq z+\lambda_{\text {min }}$ dimana $\lambda=G x$ di persamaan (2.17). Sehingga dapat ditulis

$$
G x \geq z+\lambda_{\min }
$$

Sehingga bentuk relaksasi BP ini dapat dinyatakan sebagai berikut:

$$
\begin{aligned}
& \text { BP: Minimumkan } \quad C^{T} x+e^{T} s+\gamma_{\min }^{T} x \\
& \text { Kendala } \quad Q x=y+s+\Gamma_{\text {min }} \mathrm{e} \\
& 0 \leq y \leq\left[\Gamma_{\max }-\Gamma_{\min }\right](\mathrm{e}-\mathrm{x}), \mathrm{s} \geq 0 \\
& h^{T} x+e^{T} z+\lambda_{\text {min }}^{T} x \geq g \\
& G x=z+\lambda_{\text {min }} \\
& 0 \leq z_{i} \leq\left[\Lambda_{\max }-\Lambda_{\min }\right] x \\
& x \in X
\end{aligned}
$$

Maka tranformasi persamaan linierisasi program kuadratik nol-satu selesai [6].

I. REPRESENTASI PENDEKATAN PROGRAM KUADRATIK NOL-SATU 
Berdasarkan definisi pada subbab (2.1), maka dapat mempresentasikan hubungan antara persoalan program kuadratik umumnya dengan persoalan program kuadratik nol-satu.

Lemma. 3.1 Andaikan $x \in X \subseteq\{0,1\}$ untuk

$i=1, \ldots, n$.

$x_{i} Q_{i} x=\max \left\{\gamma_{\min }^{i} x_{i}, Q_{i} x+\gamma_{\max }^{i} x_{i}-\gamma_{\max }^{i}\right\}(3.1)$

$x_{i} Q_{i} x=\min \left\{\gamma_{\text {max }}^{i} x_{i}, Q_{i} x+\gamma_{\text {min }}^{i} x_{i}-\gamma_{\text {min }}^{i}\right\}$ (3.2)

memiliki hubungan yang sama antara program

kuadratik nol satu dengan program kuadratik umumnya.

Bukti Andaikan $x_{i}=0$ maka $x_{i} Q_{i} x$ pada persamaan (3.1) jelas bernilai 0 dan sisi kanan $\max \left\{\gamma_{\min }^{i} x_{i}, Q_{i} x+\gamma_{\text {max }}^{i} x_{i}-\gamma_{\text {max }}^{i}\right\} \quad$ menjadi $\max \left\{0, Q_{i} x+-\gamma_{\max }^{i}\right\}=0$. Dan dalam kasus lainnya, andaikan $x_{i} \neq 0$, dengan kata lain $x_{i}=1$ maka sisi kanan persamaan (3.1) dapat dituliskan menjadi dimana sama dengmax $\left\{\gamma_{\text {min }}^{i}, Q_{i} x\right\}=Q_{i} x$ an sisi kirinya yaitu $Q_{i} x$. Dan begitu juga dapat dilakukan pada persaamaan (3.2)

Akibat. Andaikan $x \in X \subseteq\{0,1\}$ $\max \left\{\gamma_{\text {min }}^{i} x_{i}, Q_{i} x+\gamma_{\text {max }}^{i} x_{i}-y_{\text {max }}^{i}\right\} \leq s_{i}^{\prime}$ $s_{i}^{\prime} \leq \min \left\{\gamma_{\max }^{i} x_{i}, Q_{i} x+\gamma_{\min }^{i} x_{i}-y_{\text {min }}^{i}\right\}$

jika dan hanya jika

$$
S_{i}^{\prime}=x_{i} Q_{i} x
$$

Bukti disubtitusikan persamaan (3.1) dan (3.2), maka dapat diperoleh dan dinyatakan sebagai berikut

$$
\begin{aligned}
\mathrm{x}_{\mathrm{i}} \mathrm{Qx} & =\max \left\{\gamma_{\min }^{i} x_{i}, Q_{i} x+\gamma_{\text {max }}^{i} x_{i}-y_{\text {max }}^{i}\right\} \\
& =\min \left\{\gamma_{\text {max }}^{i} x_{i}, Q_{i} x+\gamma_{\text {min }}^{i} x_{i}-y_{\text {min }}^{i}\right\}
\end{aligned}
$$

Hasil diatas berlaku untuk $G_{i}$ dan $\lambda_{i}$ yang telah dinyatakan sebelumnya. Linierisasi berdasarkan Akibat 3.2 merupakan persoalan BP persamaan (2.21), dimana pertidaksamaan liner persamaan (2.21) tidak lain adalah persamaan (3.3). Sebenarnya, tidak semua pertidaksamaan persamaan (3.4) yang diperlukan dalam model akhir linierisasi. Untuk menunjukkan ini, pertama diperkenalkan berikut prinsip merumuskan program kuadratik nol-satu kedalam program linear piece-wise.
Proposisi 3.1Setiap program convex yang linier atau fungsi tujuan linier piece-wice dan kendala sama dengan program linier dalam arti bahwa ada proyeksi one-to-one antara kedua solusi layak.

Bukti Ditunjukkan bahwa

Minimumkan

$f(x)$

Adalah sama untuk

Minimumkan

Kendala

$$
\begin{aligned}
& t \\
& t-f(x) \geq 0
\end{aligned}
$$

Diasumsikan bahwa fungsi tujuan merupakan linear. Himpunan kendala merupakan convex dan dikarakteristik dengan pertidaksamaan linier piece-wise. Sehingga persamaan tersebut berbentuk polyhedral convex, yang harus memiliki ekspresi linear. Itu menunjukkan bahwa persamaan Proposisi 3.1 berlaku jika variabel dibatasi oleh nol atau satu. Selanjutnya ditunjukkan adanya persamaan program linier piece-wise convex untuk masalah minimisasi kuadratik nol-satu.

Proposisi 3.2 Untuk masalah minimisasi kuadratik nol-satu, ada persamaan program linier piece-wise dengan fungsi tujuan dan kendala convex.

Bukti. Maksimum beberapa fungsi linear adalah convex dan minimum concave. Kemudian persamaan (3.1) dan persamaan (3.3) pada Lemma 3.1 menyajikan masing-masing formulasi convex dan concave. Oleh karena itu, untuk setiap diberikan persoalan minimisasi kuadratik nol-satu, maka dapat diperoleh persamaan program linier piece-wise convex dengan menggunakan persamaan (3.1) dan (3.2). Perhatikan bahwa persamaan (3.1) dan persamaan (3.2) digunakan secara bersamaan ketika memenuhi persamaan kendala.

Maka sekarang dapat ditunjukkan bahwa persamaan (2.1) - (2.3) mengikuti formulasi persamaan

Minimumkan $\quad c^{T} x+\sum_{i=1}^{n} \max \left\{\gamma_{\text {min }}^{i} x_{i}, Q_{i} x+\right.$ rmaxixi-rmaxi\}

(3.7)

Kendala $\quad h^{T} x+\sum_{\mathrm{i}=1}^{\mathrm{n}} \min \left\{\lambda_{\max }^{i} x_{i}, G_{i} x+\lambda_{\min }^{i} x_{i}-\right.$ $\lambda \min i \geq \mathrm{g}$

$$
x \in X \subseteq\{0,1\}
$$


Linierisasi persamaan (3.6) - (3.8) dapat di tunjukkan dibawah ini. Persamaan (3.7) adalah setara dengan

Kendala

$$
\begin{aligned}
& h^{T} x+\sum_{\mathrm{i}=1}^{\mathrm{n}} \mathrm{z}_{\mathrm{i}} \geq \mathrm{g} \\
& z_{i} \leq \lambda_{\max }^{i} x_{i} \\
& z_{i} \leq G_{i} x+\lambda_{\text {min }}^{i} x_{i}-\lambda_{\text {min }}^{i}
\end{aligned}
$$

Karena persamaan (3.9) - (3.11) adalah relaksasi persamaan (3.6) dan persamaan (3.9) - (3.11) juga terkandung dalam persamaan (3.6). Sekarang dapat diperoleh linierisasi untuk persamaan (3.5) - (3.8), yang setara dengan $\overline{B P}$. Selanjutnya, ditunjukkan bahwa non-necessity pertidaksamaan seperti $y \geq 0$ dan $z \geq 0$ yang juga telah di teliti oleh Adam dan Forrester [7], [8]. Sehingga linierisasi yang diperoleh dengan pendekatan piece-wise convex adalah tepat.

\section{Simpulan dan Saran}

\subsection{Simpulan}

Untuk menyelesaikan persoalan program kuadratik nol-satu dalam tulisan ini adalah dengan teknik linierisasi, yaitu dengan mentranformasikan persoalan program kuadratik kebentuk persoalan program linier. Dalam teknik linierisasi Quadratic Problems $(Q P)$ diubah menjadi Bilinear Problems (BP) terlebih dahulu. Dimana, fungsi kuadratik dipecah menjadi perkalian fungsi linier. Akibat dari proses $B P$ persamaan dari fungsi kendala menjadi bertambah.

Selanjutnya $B P$ yang merupakan relaksasi dari perkalian fungsi linier kendala disubtitusikan dengan variabel yang baru. Sehingga fungsi tujuan dan kendala yang merupakan persamaan $B P$ bertransformasi menjadi persamaan linier. Aki-bat dari transformasi $B P$ maka bertambahlah persamaan pada fungsi kendala yang mengacu pada struktur perubahan $B P$. Kemudian proses selanjutnya menyederhanakan pertidaksamaan fungsi kendala dengan merelaksasi $B P$ dengan menghapus batas atas dan bawah dengan mensubtitusi persamaan yang baru.

Program kuadratik nol-satu juga dapat direpresentasikan dengan General Quadratic Programming, sebab BP memiliki hubungan yang sama dengan General Quadratic Programming. Untuk menunjukkan ini, persoalan program kuadratik nol-satu dirumuskan kedalam persoalan program linier piece-wise. Pada persoalan minimasi kuadratik nol-satu, terdapat persamaan program linier piece-wise convex. Sehingga teknik linierisasi yang diperoleh dengan piece-wise convex benar.

\subsection{Saran}

Setelah penelitian literature dilakukan teknik transformasi linier program kuadratik nol-satu disarakan untuk melakukan linierisasi apabila jumlah variabel kecil tapi apabila jumlah variabel banyak perlu dilakukan lebih lanjut.

\section{Daftar Pustaka}

W. Gharibi dan Y. Xia. A tight linearization strategy for zero-one quadratic programming problems. International Journal of Computer Science Issues: 294-299, 2012.

1. F, Furini dan E, Traversi. Extended Linear Formulation for BinaryQuadratic Problems. Paris: Universite de Paris Dauphine. 2013.

2. W. Gharibi. Improved Balas and Mazzola Linearization for Quadratic 01 Programs with Application in a New Cutting Plane Algorithm. Dept. of Computer, Science, College of Computer Science and Information Systems, Jazan University, Jazan 828226694, KSA. 2012.

M. DeSantis, dan F Rinaldi. Continuous Reformulations for ZeroOne Programming Problems. Springer Science and Business Media, LLC, 2011.

G, Kochenberger, B Alidaee, dan C, Rego. An unconstrained quadratic binary programming approach to the vertex coloring problem. Annals of Operations Research, 139(1):229241, 2005.

H.D Sherali, dan J.C. Smith. An Improved Linierization Strategy for Zero-One Quadratic Problems. Optimization Letters, vol.1,pp.33-47. 2007

W. Adams, and R. Forrester. ASimple Approach for Generating Concise Linear Representations of Mixed 0-1 Polynomial Programs. Operations Research Letters, vol. 33, no. 1, pp. 55-61, 2005.

W. Adams, and R. Forrester. Linear Forms of Nonlinear Expressions: New Insights on Old Ideas. Operations Research Letters, vol. 35, no. 4, pp. 510, 2007 